\title{
Gray Assessment of Equipment Maintenance Support Capability Based on the Structure Entropy Weight Method
}

\author{
Tao Huang ${ }^{1,2}$, Jiaqi Xiang ${ }^{3}$, and Hongmin $\mathrm{Yu}^{1}$ \\ ${ }^{1}$ Academy of Joint Logistic, NDU, 100089 Beijing, China \\ ${ }^{2}$ Army Academy of Military Transportation, 300161 Tianjin, China \\ ${ }^{3}$ Academy of Equipment, 101400 Beijing, China
}

\begin{abstract}
The influencing factors which about equipment maintenance support abilities are analysed and the index system that is used to evaluate equipment support abilities are constructed in the paper. Then, the weight of the index is determined by the structure entropy weight method which is a combination of qualitative and quantitative. The comprehensive evaluation model of equipment maintenance support abilities are constructed by combining gray clustering evaluation theory. Finally, the feasibility and validity of the model are verified by an example.
\end{abstract}

\section{Introduction}

Equipment maintenance and support capability is an important capability index of equipment supportability [1], which is also an important factor of maintaining and restoring equipment in good condition and generating combat effectiveness. To assessing equipment maintenance support capability of equipment maintenance support system, can reflect the objective nature of military equipment maintenance support capability fully and truly, and examine if the maintenance and support resources, program, and objects match each other. Through this, Commanders can grasp the maintenance support capability of the troops. It specifies the future construction direction of equipment maintenance and support, and has a strong practical significance.

\section{Analysis on influencing factors of equipment maintenance support capability}

\subsection{Equipment maintenance quality}

Equipment maintenance quality is an inherent property of equipment [2]. It includes reliability, maintenance, supportability, testability and survivability. Different equipment maintenance quality is bound to have different requirements in element producing of maintenance and support systems, and direct impact on selection of way and formation on equipment maintenance.

\subsection{Maintenance and support staff}

The maintenance and support staff is the main body of maintenance and support activities [3]. Its quality is a key factor in determining maintenance and support capabilities. Whether specific technical work of maintenance support activities, or management activities, it is only through human activity, can maximize the potential of the elements, and transform them into tangible support capabilities.

\subsection{Maintenance measures and facilities}

As the material basis of maintenance work implementation, the integrity, capability of complement and performance have great impact in environment adapting ability, maintenance efficiency, security and economic efficiency [4]. The modernization degree of maintenance tools and facilities is an important symbol of maintenance support capability, which is also an important aspect of maintenance support system construction.

\subsection{Spares}

Spare is a material foundation of reparation. Its store and supply operation mechanism may directly affect the maintenance and support capabilities. It reflects in following two aspects: First, spare security is an important factor affecting the rate of good condition equipment. Second, the supply of spares will directly impact on repair capabilities and readiness war wounds equipment. The fastest and most effective way of equipment War wounds repair and troubleshooting is to change parts. That spares supply fast enough can win time for replacement parts repairing. In a sense, the rapid repair capacity of equipment dependents on reliable spares support. 


\subsection{Maintenance management}

The three basic function of maintenance management are plan, organization and controlling [5]. The maintenance activity is based on scientific plan, which is the primary function of maintenance management. Organization is the guarantee of plan implementation, which is an important condition on implementing control functions. Controlling is the basis of organization existence in order to implement programs effectively. Plan, organization and controlling are a chain, which form a closed loop on maintenance management as basic activities.

\section{Construct the equipment maintenance support capability index system}

According to the analysis on influence factors of equipment maintenance support capability, we choose 60 initial evaluation indexes as basis of the evaluation system. We investigate and adjust primary evaluation indexes and finally confirm it by using Delphi Survey Method. It contains 6 first-level indexes, which are quality equipment, human resources, maintenance management, environment climate, the repair economy, spare parts support and mobility [6], and 16 secondary indexes, as table 1.Corresponding index means as follows:

(1) Number of special maintenance equipment

The number of professional tools used on repair service for all maintenance types.

(2)Mean time to repair

The average of time needed to repair equipment.

$$
\overline{m_{c i}}=\frac{1}{n}\left(t_{1}+t_{2}+\cdots t_{n}\right)=\frac{1}{n} \sum_{t=i}^{n} t_{i}
$$

Where: $t_{i}-$ the maintenance time observed and measured each time; $n$-the number of observations

(3) equipment malfunction detection rate

Detected percentage of all malfunction in tested items, which occur in a predetermined time under predetermined conditions and using a predetermined method. Namely:

$$
r=\left(N_{D} / N_{r}\right) \times 100 \%
$$

Where: $r$-malfunction detection rate; $N_{r}-$ All failure rates occur in specified time; $N_{D}$-the number of correctly tested failures under determined conditions and using a predetermined method

(4)the rate of equipment in perfect condition

The percentage of good condition equipment in formation number

$$
\lambda=\left(k_{1} / w_{m}\right) \times 100 \%
$$

Where: $\lambda$-the rate of equipment in perfect condition; $k_{1}$-the number of good condition equipment; $w_{m}$-the number of formation equipment

(5) Percentage of professional and technical personnel

Percentage of professional and technical personnel $=($ the number of professional and technical personnel $/$ the number of existing personnel)

\begin{tabular}{|c|c|c|c|}
\hline \multicolumn{2}{|c|}{ evaluation index } & $\begin{array}{l}\text { the ability } \\
\text { reflected }\end{array}$ & measure index \\
\hline \multirow{16}{*}{$\begin{array}{c}\text { the } \\
\text { evaluation } \\
\text { index } \\
\text { System of } \\
\text { Equipment } \\
\text { Maintenanc } \\
\text { e Support } \\
\text { Capability }\end{array}$} & \multirow{4}{*}{$\begin{array}{l}\text { quality } \\
\text { equipment }\end{array}$} & $\begin{array}{l}\text { equipment } \\
\text { matching } \\
\text { capability }\end{array}$ & $\begin{array}{l}\text { number of } \\
\text { special } \\
\text { maintenance } \\
\text { equipment }\end{array}$ \\
\hline & & $\begin{array}{l}\text { maintenance } \\
\text { ability }\end{array}$ & $\begin{array}{c}\text { Mean time to } \\
\text { repair }\end{array}$ \\
\hline & & $\begin{array}{c}\text { the ability of } \\
\text { equipment } \\
\text { testing }\end{array}$ & $\begin{array}{c}\text { Equipment } \\
\text { malfunction } \\
\text { detection rate }\end{array}$ \\
\hline & & $\begin{array}{l}\text { equipment } \\
\text { availability }\end{array}$ & $\begin{array}{c}\text { Equipment in } \\
\text { perfect } \\
\text { condition } \\
\end{array}$ \\
\hline & \multirow{3}{*}{$\begin{array}{l}\text { human } \\
\text { resources }\end{array}$} & $\begin{array}{l}\text { Staffing } \\
\text { structure }\end{array}$ & $\begin{array}{c}\text { Percentage of } \\
\text { professional } \\
\text { and technical } \\
\text { personnel }\end{array}$ \\
\hline & & $\begin{array}{l}\text { education } \\
\text { level }\end{array}$ & $\begin{array}{l}\text { percentage } \\
\text { with } \\
\text { certificates }\end{array}$ \\
\hline & & $\begin{array}{l}\text { level of } \\
\text { training }\end{array}$ & training time \\
\hline & \multirow{2}{*}{$\begin{array}{l}\text { environment } \\
\text { and climate }\end{array}$} & $\begin{array}{c}\text { cultural } \\
\text { environment }\end{array}$ & qualitative \\
\hline & & $\begin{array}{l}\text { geographical } \\
\text { environment }\end{array}$ & description \\
\hline & \multirow{2}{*}{$\begin{array}{l}\text { maintenance } \\
\text { economic }\end{array}$} & economic & $\begin{array}{l}\text { Transport and } \\
\text { package costs }\end{array}$ \\
\hline & & $\begin{array}{c}\text { Financial } \\
\text { benefits }\end{array}$ & $\begin{array}{c}\text { Savings funds } \\
\text { rate }\end{array}$ \\
\hline & \multirow{3}{*}{$\begin{array}{c}\text { maintenance } \\
\text { managemen } \\
\mathrm{t}\end{array}$} & $\begin{array}{c}\text { management } \\
\text { tools }\end{array}$ & \\
\hline & & $\begin{array}{l}\text { Information } \\
\text { resource }\end{array}$ & $\begin{array}{l}\text { qualitative } \\
\text { description }\end{array}$ \\
\hline & & $\begin{array}{l}\text { System of } \\
\text { command }\end{array}$ & \\
\hline & \multirow{2}{*}{$\begin{array}{c}\text { Spare } \\
\text { parts and } \\
\text { maintenance } \\
\text { Mobile } \\
\text { support }\end{array}$} & $\begin{array}{c}\text { Spare } \\
\text { performance }\end{array}$ & $\begin{array}{c}\text { Spares } \\
\text { inventory rate } \\
\end{array}$ \\
\hline & & $\begin{array}{l}\text { Maneuver } \\
\text { support } \\
\text { capability }\end{array}$ & $\begin{array}{l}\text { Pass rate per } \\
\text { unit time }\end{array}$ \\
\hline
\end{tabular}

Table 1. Equipment maintenance support capability assessment index system.

(6) percentage with certificates

(The number of certificated personnel /the number of existing personnel)

(7)training time

Sum time of professional maintenance training courses measured by week.

(8)transport and package costs

Sum cost of transport and package on equipment maintenance and spares.

(9)saving funds rate

Saving funds rate is the percentage of actual expenditure and plan expenditure.

Savings funds rate $=($ actual pay $/$ plan pay $)$

(10)spares inventory rate

Spares inventory rate $=$ (the number of existing spares/ the number of promising spares)

(11)pass rate in unit time 
The percentage of equipment going through an area in unit time and the total motorized equipment in specified time

Unit time passing rate $=$ (number of actual equipment/number of all motorized equipment)

\section{The gray clustering comprehensive evaluation model based on the structure entropy weight method}

\subsection{Determine the index weight}

Index weight must be determined by index importance degree in comprehensive evaluation. Methods of weight determination include subjective methods, objective methods, and the combination. Subjective weighting method is poor in objectivity, but strong in explanatory. Objective weighting method gets weight relying on certain rules. In most case, it gains high accuracy, but sometimes is inconsistent with the actual situation. It is poor in explanatory. It can't give a clear explanation to the results. In the paper, we use Structure Entropy Weight Method which combines with subjective and objective method to determine the weight.

The Structure Entropy Weight Method [7] is an analysis method based on entropy theory, which combines with qualitative analysis and quantitative analysis. The basic idea is to combine the Delphi expert survey method and fuzzy analysis method, make quantitative analysis with entropy theory in weight sorted structure. Through analyzing systematic index and their relationship, we broke down them into a mutually different hierarchy structure, and determine the index weight in each level with relative importance sorting structure.

Steps of determining index weight with Structure Entropy Weight Method are as follows:

Step1: gather expert opinions, form typical sort

Gather expert opinions with "Delphi Method." First, design expert survey tables on index weight (as table 2 ) . According to procedures and requirements of "Delphi method", we prescribe questionnaires to a number of experts. Experts should be representation, authority, impartiality, and familiar with evaluation objects. Experts fill out an anonymous questionnaire. It means that experts should give out their own qualitative judgment based on their expert knowledge and experience to the index importance sequence opinions (using" $\sqrt{ }$ "). Through consultation and feedback, we finally form the experts sort opinions, which we call typical sort.

Step2: blind degree analysis about typical sort

Because of data noise, the typical sorted opinions tend to have potential bias and traceability data uncertainty. To eliminate data noise and reduce uncertainty, the qualitative judgments conclusion of typical sorted opinions table indexes is needed to statistical analysis and process. It means to measure the entropy, for reducing experts' typical sorted uncertainty. Specific method as follows:
Table 2. Experts survey table.

\begin{tabular}{|c|c|c|c|c|c|}
\hline $\begin{array}{c}\text { Index } \\
\text { type }\end{array}$ & number & $\begin{array}{r}\text { First } \\
\text { Choice } \\
\end{array}$ & $\begin{array}{l}\text { second } \\
\text { choice }\end{array}$ & $\begin{array}{c}\text { third } \\
\text { choice }\end{array}$ & $\begin{array}{c}\text { forth } \\
\text { choice }\end{array}$ \\
\hline \multirow{3}{*}{$\begin{array}{c}\text { Index } \\
1\end{array}$} & 1 & $\sqrt{ }$ & & & \\
\hline & 2 & & $\sqrt{ }$ & & \\
\hline & 3 & $\sqrt{ }$ & & & \\
\hline \multirow{3}{*}{$\begin{array}{c}\text { Index } \\
2\end{array}$} & 1 & & $\sqrt{ }$ & & \\
\hline & 2 & $\sqrt{ }$ & & & \\
\hline & 3 & & & $\sqrt{ }$ & \\
\hline \multirow{3}{*}{$\begin{array}{c}\text { Index } \\
3\end{array}$} & 1 & & $\sqrt{ }$ & & \\
\hline & 2 & & & $\sqrt{ }$ & \\
\hline & 3 & & & $\sqrt{ }$ & \\
\hline $\begin{array}{l}\text { instru } \\
\text { ction }\end{array}$ & \multicolumn{5}{|c|}{$\begin{array}{l}\text { According to your opinion on the importance of above } \\
\text { indexes, please sort them reasonable. For example, if } \\
\text { you think index } 2 \text { should be the most important in } \\
\text { index category, you draw " } \sqrt{ } \text { in first choice place, the } \\
\text { same to others. Allow several indicators considered to } \\
\text { be equally important point, in turn draw " } \sqrt{ } \text { in the } \\
\text { corresponding place. }\end{array}$} \\
\hline
\end{tabular}

The number of experts participating in the survey is " $k$ ", and get $k$ sheets counseling statement. Each table corresponds to a set of indexes, denoted $U=\left\{u_{1}, u_{2}, \cdots\right.$ $\left.u_{\mathrm{n}}\right\}$.The typical sorted array corresponding to index denoted $\left(a_{i 1}, a_{i 2}, \cdots a_{i n}\right)$. The sorted matrix obtained from $k$ tables is denoted $A\left(A=\left(a_{i j}\right)_{k \times n} i=1,2, \cdots k ; j=1,2, \cdots n\right)$. We call it index typical sorted matrix. $a_{i j}$ is the value that expert $i$ evaluate index $u_{j}$.

Transform above typical sorted quantitative, and define membership function of qualitative sorted transformation as:

$$
\chi(I)=-\lambda p_{n}(I) \ln p_{n}(I)
$$

Define $p_{n}(I)=\frac{m-I}{m-1}$, and $\lambda=\frac{1}{\ln (m-1)}, " I "$ is the qualitative sorted number which experts give when they evaluate some index according to typical sorted format. if it considers that indicator $\mathrm{A}$ is the first choice in four indicators $A, B, C, D$, then " $I$ " equal to 1 .If considered as the second choice, " $I$ " equal to 2 , and so on. Here $\chi$ is a variable value defined in $[0,1] \cdot \chi(I)$ is a corresponding membership function value of $I . I=1,2, \cdots j, j+1 . " j "$ is the actual maximum sequence number. For example, when $j=4$, it means that four indicators participate sorting, and the maximum value of the sequence number equal to 4 . $m$ is the conversion parameter, order $m=j+2$, named $m=6$.

When $I=1, \quad p_{n}(1)=\frac{m-1}{m-1}=1 ;$

When $I=j+1$ take the largest number,

$$
p_{n}(j+1)=\frac{(j+2)-(j+1)}{(j+2)-1}=\frac{1}{j+1}>0
$$

So, $0 \leq p_{n} \leq 1$, put $p_{n}$ to (4), after simplification, we get:

$$
\chi(I) /\left(\frac{m-I}{m-1}\right)-1=\frac{\ln (m-I)}{\ln (m-1)}
$$

Order $\chi(I) /\left(\frac{m-I}{m-1}\right)-1=\mu(I)$, 
Then $\mu(I)=\frac{\ln (m-I)}{\ln (m-1)}$

Substituting the sorted number $I=a_{i j}$ into above formula, we obtain $b_{i j}\left(\mu\left(a_{i j}\right)=b_{i j}\right)$ as the quantitative conversion value of $a_{i j}$.

We call $b_{i j}$ the membership of sorted numbers $I$, and matrix $B=\left(b_{i j}\right)_{k \times n}$ the membership matrix. We give the same right to $k$ experts about $u_{j}$ index, which is to measure the "consensus" of $u_{j}$ index from $k$ experts. It is known as the average understanding degree, denoted $b_{j}$, so: $b_{j}=\left(b_{1 j}+b_{2 j}+\ldots+b_{k j}\right) / k$.

Define $Q_{j}$ as understanding implicit uncertainty from expert $z_{i}$ to $u_{j}$ factor, called blind understanding degree. Then,

$$
Q_{j}=\left|\left\{\left[\max \left(b_{1 j}, b_{2 j}, \ldots, b_{k j}\right)-b_{j}\right]+\left[\min \left(b_{1 j}, b_{2 j}, \ldots, b_{k j}\right)-b_{j}\right]\right\} / 2\right|
$$

Obviously, $Q_{j} \geq 0$.

For each $u_{j}$ factor, we define overall understanding degree from $k$ experts to $u_{j}$, denoted $x_{j}, x_{j}=b_{j}\left(1-Q_{j}\right)\left(x_{j}>0\right)$.

We can get the evaluation vector from $k$ experts by $x_{j}, X=\left(x_{1}, x_{2}, \cdots x_{\mathrm{n}}\right)$.

Step3: normalization process

To obtain the weight of $u_{j}$ index, we make $x_{j}=b_{j}\left(1-Q_{j}\right)$ to be normalized.

define $\alpha_{j}=x_{j} / \sum_{i=1}^{n} x_{j}$, obviously : $\alpha_{j}(j=1,2, \ldots, n)>0$, and $\sum_{j=1}^{n} \alpha_{j}=1$, so $\left(\alpha_{1}, \alpha_{2}, \ldots, \alpha_{n}\right)$ is the consistency overall judgment of importance to factors $U=\left\{u_{1}, u_{2}, \cdots u_{\mathrm{n}}\right\}$ from $k$ experts, which is consistent with wishes from $\mathrm{k}$ experts group. Note $W=\left\{\alpha_{1}, \alpha_{2}, \cdots, \alpha_{\mathrm{n}}\right\}$ as the weight vector of $U=\left\{u_{1}, u_{2}, \cdots u_{\mathrm{n}}\right\}$ factor set.

We use Structure Entropy Method to determine the weight of each index in equipment maintenance support capability index system about an artillery brigade in west area, and ultimately get:

The weight vector of first-level index factor set $U=\left\{u_{1}, \cdots, u_{6}\right\}$ is $W=\{0.234,0.25,0.176,0.078,0.157,0.105\}$, corresponding to each index as follows:

$\alpha_{1}$ Equipment quality $=0.234$,

$\alpha_{2}$ Human resources $=0.25$,

$\alpha_{3}$ Environment climate $=0.176$,

$\alpha_{4}$ Repair economic $=0.078$,

$\alpha_{5}$ Maintenance management $=0.157$,

$\alpha_{6}$ Maintenance spare parts and motor protection $=0.105$.

The weight vector of second-level index factor set $U_{1}=\left\{u_{11}, u_{12}, u_{13}, u_{14}\right\}$ is $W_{1}=\{0.225,0.025,0.395,0.355\}$, corresponding to each index as follows:

$\alpha_{11}$ Supporting index $=0.225$,

$\alpha_{12}$ Maintainability index $=0.025$,

$\alpha_{13}$ Test index $=0.395$,

$\alpha_{14}$ Availability index $=0.355$.

The weight vector of second-level index factor set $U_{2}=\left\{u_{21}, u_{22}, u_{23}\right\}$ is $W_{2}=\{0.225,0.5,0.125\}$, corresponding to each index as follows:

$\alpha_{21}$ Preparation of proportion index $=0.225$, $\alpha_{22}$ Education level indicator $=0.5$,

$\alpha_{23}$ Training level index $=0.125$.

The weight vector of second-level index factor set $U_{3}=\left\{u_{31}, u_{32}\right\}$ is $W_{2}=\{0.5,0.5\}$, corresponding to each index as follows:

$\alpha_{31}$ Cultural environment index $=0.5$,

$\alpha_{32}$ Geographical environment index $=0.5$,

The weight vector of second-level index factor set $U_{4}=\left\{u_{41}, u_{42}\right\}$ is $W_{4}=\{0.625,0.375\}$, corresponding to each index as follows:

$\alpha_{41}$ Economic index $=0.625$,

$\alpha_{42}$ Financial benefit index $=0.375$.

The weight vector of second-level index factor set $U_{5}=\left\{u_{51}, u_{52}, u_{53}\right\}$ is $W_{2}=\{0.35,0.355,0.395\}$, corresponding to each index as follows:

$\alpha_{51}$ Management tool index $=0.35$,

$\alpha_{52}$ Information resource index $=0.355$,

$\alpha_{53}$ System of command index $=0.395$.

The weight vector of second-level index factor set $U_{6}=\left\{u_{61}, u_{62}\right\}$ is $W_{6}=\{0.875,0.125\}$, corresponding to each index as follows:

$\alpha_{61}$ Spare performance index $=0.875$,

$\alpha_{62}$ Maneuver support index $=0.125$.

\subsection{Construct integrated assessment model}

There are many methods about equipment maintenance support capability assessment, such as principal component analysis, analytic hierarchy process, fuzzy comprehensive evaluation, artificial neural network, gray clustering method. Principal component analysis can eliminate the overlap between information and indicators in higher correlation evaluation among indexes [8]. It can automatically generate the right by mathematic according to index information, and avoid bias caused by human factors. It is suitable for comprehensive evaluation with more samples, but undue reliance on objective data. As an evaluation method, AHP has applicability, simplicity and systematic characteristics, which can be used as an indicator to determine the weights [9]. However, the subjective judgment and choose of people has a larger effect on the results in AHP process, whether establish a hierarchy or judgment matrix. It makes the method with great subjective decisions. Fuzzy comprehensive evaluation method requires giving accurate fuzzy membership function in process. It's very difficult in actual use. Artificial neural network for comprehensive post-evaluation has its own shortcomings. First, its error back propagation through the output layer, the more hidden layer, the error will be more unreliable when closer to the input layer, which affects efficiency and convergence rate learning in a certain extent [10]. The second is that training and learning the structured network model by gaining knowledge and experience from evaluation experts, requires more learning samples, which is more difficult to select in the same condition and background to evaluated projects [11].

Gray clustering method identifies other unknown system information by partially known information. 
There is no strict requirement about the sample, and doesn't need to know the sample distribution. It's simple calculation, flexible and wide range use. Because the gray system theory has advantages in handling poor information, we can combine gray system theory with clustering methods, create more appropriate model. It will be well applied to equipment maintenance support capability assessment. The gray clustering evaluation method is very suitable to equipment maintenance support capability assessment.

The establishment and step of gray clustering assessment model are as follows:

Suppose $n$ clustering objects, $m$ clustering indexes, $s$ different gray category. According to the $i$ objects $(i=1,2, \ldots, n)$ on $j=(1,2, \ldots, m)$ indexes sample value $X_{i j}$, classify $i$ objects to the $k$ section ash called gray clustering. Equipment maintenance support capability assessment take the quality of equipment, human resources, environment and climate, maintenance of economic, maintenance management, maintenance, spare parts and motor protection as clustering objects, the sub-indexes of each them as clustering index.

The first step: in accordance with the evaluation requirement divided gray number $s$, we divide the range of each index into $s$ Ash classes. For example, the value range of $k$ gray class from indicator $j$ is denoted as $\left[x_{j}^{k}(l), x_{j}^{k}(u)\right]$. The up and low value of this gray class $\left(x_{j}^{k}(l), x_{j}^{k}(u)\right)$ is generally determined by actual situation or qualitative findings. In the paper, we divide gray level to five classes, $e=1,2,3,4,5$ (excellent, good, fair, poor, very poor).

Step two: define $f_{j}^{k}(\cdot)$ whiten function of index $j$ on $k$ subclass the typical whiten function as figure 1:

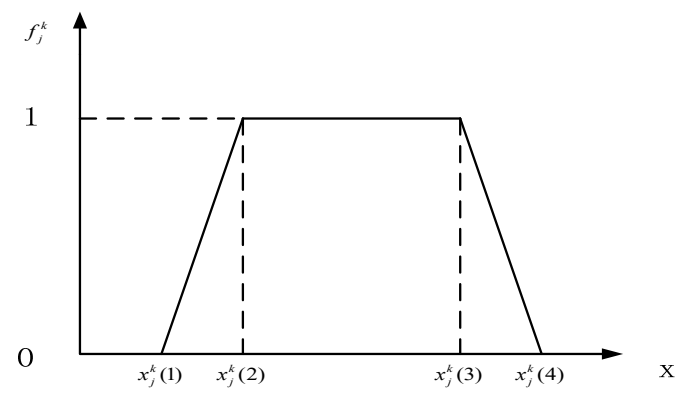

Fig. 1. Typical Whiten Function.

Among them, $x_{j}^{k}(1), x_{j}^{k}(2), x_{j}^{k}(3), x_{j}^{k}(4)$ are turning points of $f_{j}^{k}(\cdot)$, a typical whiten weight function written as: $f_{j}^{k}\left[x_{j}^{k}(1), x_{j}^{k}(2), x_{j}^{k}(3), x_{j}^{k}(4)\right]$. According to the turning point existing or not, a typical whiten weight function can evolve to lower whiten weight test function, moderate test whiten weight function and limit test whiten weight function, denoted as follows:

$f_{j}^{k}\left[-,-, x_{j}^{k}(3), x_{j}^{k}(4)\right], f_{j}^{k}\left[x_{j}^{k}(1), x_{j}^{k}(2),-, x_{j}^{k}(4)\right], f_{j}^{k}\left[x_{j}^{k}(1), x_{j}^{k}(2),-,-\right]$. According to the image of various whiten weight functions, we can get the segmented expression of whiten weight function.
Step three: calculate the integrated clustering coefficient of object $i(i=1,2, n)$ on the gray class $k(k=$ $1,2, \cdots, s): \sigma_{i}^{k}=\sum_{j=1}^{m} f_{j}^{k}\left(x_{i j}\right) \times \eta_{j}, \eta_{j}$ is the weight of index $j$.

$$
\sum=\left(\sigma_{i}^{k}\right)=\left[\begin{array}{cccc}
\sigma_{1}^{1} & \sigma_{1}^{2} & \cdots & \sigma_{1}^{s} \\
\sigma_{2}^{1} & \sigma_{2}^{2} & \cdots & \sigma_{2}^{s} \\
\cdots & \cdots & \cdots & \cdots \\
\sigma_{n}^{1} & \sigma_{n}^{2} & \cdots & \sigma_{n}^{s}
\end{array}\right]
$$

Step four: If $\max _{1 \leq k \leq s}\left\{\sigma_{i}^{k}\right\}=\sigma_{i}^{k^{*}}$, we can say that the clustering object $i$ belongs to gray class $k^{*}$.

Step five: denote gray class vector as follows:

$$
k_{i}^{*}=\left(k_{i 1}^{*}, k_{i 2}^{*}, \cdots, k_{i m}^{*}\right)^{T}
$$

Step six: calculate the comprehensive gray coefficient of $i$ evaluation object.

$$
g_{i}=\delta_{i} \times k_{i}^{*}=\left(\delta_{i 1}, \delta_{i 2}, \cdots \delta_{i m}\right)\left(k_{i 1}^{*}, k_{i 2}^{*}, \cdots, k_{i m}^{*}\right)^{T}
$$

Step seven:

When $g_{i} \in\left[1+\frac{(k-1)(s-1)}{s}, 1+\frac{k(s-1)}{s}\right]$, evaluation objects $i$ belong to $k$ gray class.

Step eight: calculate the comprehensive gray coefficient of overall evaluation goal $G$, when

$G \in\left[1+\frac{(k-1)(s-1)}{s}, 1+\frac{k(s-1)}{s}\right]$,

the comprehensive evaluation of object $I$ belongs to $k$ gray class, that we get the evaluate conclusion.

\section{Case analyze}

The above equipment maintenance and support capability evaluation index system and model can be applied to evaluate the equipment maintenance and support capabilities of artillery brigade. Firstly, we can evaluate various factors from the lowest level. The comprehensive assessment can be made to the upper layer. By evaluating from lowest to the highest, we can get the overall assessment results. When the evaluated results come out from the lower index, we make matrix multiplication with the upper index weights, and finally get a set of comprehensive evaluation results with gray clustering information.

Firstly, we calculate the gray evaluation coefficients about first indexes

$\left(g_{1}, g_{2}, g_{3}, g_{4}, g_{5}, g_{6}\right)^{\mathrm{T}}=(2.725,4.125,2.75,3.875,3.25,2.125)^{\mathrm{T}}$. According to formula (6),

$\mathrm{G}=(0.234,0.25,0.176,0.078,0.157,0.105) \times(2.725,4.125,2$. $75,3.875,3.25,2.125)^{\mathrm{T}}=3.189$. When $k=3, s=5$;

$\mathrm{G}=3.189 \in\left[1+\frac{(k-1)(s-1)}{s}, 1+\frac{k(s-1)}{s}\right]=[2.6,3.4]$.

According to gray class, it is the fair level. Through research, it shows that the result is consistent with the actual situation.

\section{Conclusions}

Using structural entropy method to determine index weight of equipment maintenance support capacity index system, can overcome the shortcomings of single index weight determination method, has strong explanatory 
and high accuracy. Gray clustering assessment theory has advantages on dealing with poor information and less data evaluation .It is simple calculation and wide application. The evaluation model of equipment maintenance support capability constructed by structural entropy method and gray clustering evaluation theory can avoid large data requirements and minimize the influence of human factors, which has strong credibility and validity. The feasibility and effectiveness can be showed from the example of equipment maintenance and support capability evaluation of artillery brigade. It provides a new theoretical basis for troops to understand the present supporting situation and find their own shortcomings and deficiencies.

\section{References}

1. C. L. Chen, O. Qi, Y. Liu. Distribution Calculation Model of Armored Equipment Maintenance Workload. J. Journal of Dong Hua University, 6(2015).

2. F. Li, Z. X. Zhu. Choosing the better chemical defense equipment support program based on gray clustering and fuzzy network analysis. J. Chemical Defence Report, 5(2011)

3. Y. Cui, S. J. Chen. Research and Application of Maintenance Decision Method of Complex Equipment in Nuclear Power Plant. J. Journal of Dong Hua University,2(2016)
4. X. Li, X. S. Li, Z. Q. Xu. Research of Fuzzy Comprehensive Assessment on aerospace test equipment support capability. J. Equipment College report, 2(2012)

5. Z. T. Liu, X. M. Du, F. Li. Indicators to assess the effectiveness of Equipment Maintenance Support Systems. J. Sichuan Ordnance report, 10(2009)

6. Q. Y. Cheng. Command effectiveness assessment and risk management Based on information system (NDUP, Beijing, 2011)

7. G. Y. Wu, B. B. Zhang. Workspace and dynamic performance evaluation of the parallel manipulators in a spray-painting equipment. J. Robotics and Computer Integrated Manufacturing, 2016

8. M. K. Ghorabaee, M. Amiri. A new hybrid fuzzy MCDM approach for evaluation of construction equipment with sustainability considerations. J. Archives of Civil and Mechanical Engineering, 2017.

9. Z. J. Huang, Q. Zhu, S. Y. Liu. Research on Forecast Model of Spare Parts Consumption. J. Procedia Engineering, 2017

10. S. Pang, Y. X. Jia. Study on Simulation Modeling and Evaluation of Equipment Maintenance. J. Journal of Shanghai Jiao Tong University, 5(2016)

11. S. F. Liu, Y. G. Dang, Z. G. Fang. Gray system theory and application (Sciences Press, 2004) 